\title{
A common methodology for risk assessment and mapping for south-east Europe: an application for heat wave risk in Romania
}

\author{
Maria Papathoma-Koehle ${ }^{1}$ - Catrin Promper ${ }^{2}$. \\ Roxana Bojariu ${ }^{3} \cdot$ Roxana Cica $^{3}$ - András Sik ${ }^{4}$. \\ Kinga Perge ${ }^{4} \cdot$ Peter László $^{4} \cdot$ Erika Balázs Czikora $^{4}$. \\ Alexandru Dumitrescu ${ }^{3}$ - Cosmin Turcus ${ }^{5}$ - Marius-Victor Birsan ${ }^{3}$. \\ Liliana Velea ${ }^{3}$ - Thomas Glade ${ }^{2}$ \\ Received: 4 June 2014/ Accepted: 6 June 2014 / Published online: 24 March 2016 \\ (C) The Author(s) 2016. This article is published with open access at Springerlink.com
}

\begin{abstract}
Assessment of risk considering both the probability of occurrence of a natural phenomenon and its consequences on the elements at risk is an essential step before the design of adequate risk reduction strategies in local, regional or national level. Within the EU-funded project SEERISK "Joint disaster management risk assessment and preparedness for the Danube macro-region", a common methodology for risk assessment and mapping for climate change-related hazards has been developed. Vulnerability assessment is a large part of the risk assessment procedure, and it requires a considerable amount of detailed data. The methodology for risk assessment presented here is in line with the EC Guidelines for Risk Assessment and Mapping, and it provides alternatives in order to tackle the problem of varying data quality and quantity necessary for the analysis of hazard and vulnerability. In the present study, the methodology is adapted for heat waves and is applied in the city of Arad, Romania. Based on data regarding surface temperatures and emergency services interventions from past events during the daytime and the night-time, two hazard and two impact maps were developed, respectively, as well as a risk matrix for the night- and the daytime. A heat wave risk map was then developed that can be used by the emergency planners and services in order to prioritise their actions and focus on the hotspots as far as potential victims are concerned. The results of the case study apart from
\end{abstract}

Maria Papathoma-Koehle

maria.papathoma-koehle@boku.ac.at

1 Institute of Mountain Risk Engineering, University of Natural Resources and Life Sciences, PeterJordan-Straße 82, 1190 Vienna, Austria

2 Department of Geography and Regional Research, University of Vienna, Universitätsstrasse 7, 1010 Vienna, Austria

3 National Meteorological Administration, Climate Research Group, 97 Sos. Bucuresti-Ploiesti, 013686 Bucharest, Romania

4 National Directorate General for Disaster Management (NDGDM), H-1149 Budapest, Mogyorodi ut 43, Budapest 1903, Hungary

5 Emergency Situations Inspectorate "Vasile Goldiş" of Arad County (ISUJ Arad), Strada Andrei Saguna nr, 66-72, Arad, Romania 
providing a tool for decision-makers and emergency planers also demonstrate the applicability of the common risk assessment methodology developed as being a profound theoretical basis for distinct risk-mapping exercises.

Keywords Risk assessment $\cdot$ Risk-mapping $\cdot$ Heat waves

\section{Introduction}

\subsection{Background}

As the magnitude and frequency of climate-related hazards are expected to increase in the coming years, authorities, scientists, emergency planners and other stakeholders are in need of methodologies and tools in order to assess and visualise the spatial pattern of risks related to these hazards. A large part of the risk assessment procedure is the assessment of the vulnerability of the elements at risk to the specific hazard. Vulnerability has many dimensions, and it can be expressed in different ways according to the end-user and their needs. In this chapter, a common methodology for risk assessment for climate changerelated hazards is presented through an application example for heat waves in Romania giving special emphasis to the vulnerability part of the risk assessment procedure.

The IPCC (2012) defines heat wave and warm spell as "a period of abnormally hot weather". According to the IPCC (2012) report, "it is very likely that the length, frequency, and/or intensity of warm spells or heat waves will increase over most land areas" (p. 25). Moreover, these temperature extremes are expected not only to have direct consequences on the population but also indirect ones by affecting other phenomena such as slope instabilities and floods (IPCC 2012). As far as Europe is concerned, the IPCC report clearly suggests that projections and observations identify specific urban areas where increased heat waves are expected. Cities and urban areas suffer often higher temperatures than rural areas due to the heat island effect. According to Wilhelmi and Hayden (2010), the distribution of heat within urban areas depends on local climatology and urban meteorology combined with urban land-use patterns. The heat island effect is attributed to a number of factors including increased absorption and reflection of the sun on concrete, reduced cooling due to airflow obstruction of buildings, and heat release form industry and transport (Buscali et al. 2012). The urban heat island represents the difference in temperature between cities and the surrounding rural areas (Depietri et al. 2011). In Europe, the UHI ranges from 2 to $12{ }^{\circ} \mathrm{C}$ (Koppe et al. 2004). Koppe et al. (2004) provide a list of European cities and the associated maximum UHI. Additionally, in urban areas, the increased temperature may also be responsible for the increase of pollutants in the atmosphere (Buscali et al. 2012). The impact of a heat wave depends not only on the temperature itself but also on the frequency of high temperatures over a longer time period, on the daily and nightly minimum temperatures, and on the time of the year that they occur (Smoyer-Tomic et al. 2003). However, the consequences of the heat waves are not always related to the hazard itself but also to the characteristics of the population in the affected area (IPCC 2012). People with pre-existing health problems, socially isolated elderly people with fragile health condition, young children, people suffering from obesity, etc. are particularly vulnerable to heat waves (IPCC 2012). Therefore, heat waves are expected to have more severe impacts in the future not only due to climate change but also due to increase in urban and ageing populatio (Senf and Lakes 2011). It is, therefore, essential for 
the local authorities and emergency services to be able to identify and locate vulnerable groups of people or areas where medical intervention is required within an urban area during a heat wave (Buscali et al. 2012).

According to IPCC (2012), heat waves have increased in frequency and duration in most of Europe while major European cities are in particular risk. The urban heat island effect poses an additional risk to the population while building characteristics, population increase, emissions and lack of green spaces intensify the impact of the heat waves (IPCC 2012). The most significant heat wave events that have affected European countries in the last decades and were recorded within the EM-DAT database are listed in Table 1.

The PESETA project (Projection of Economic impacts of climate change in Sectors of the European Union based on bottom-up analysis) estimates 86,000 extra deaths per year in EU countries with a global mean temperature increase of $3{ }^{\circ} \mathrm{C}$ in $2071-2100$ in comparison with the period 1961-1990 due to the increase of the elderly population (WHO Regional Office for Europe 2008; Ciscar 2009). Moreover, a study in 200 European regions showed that the changes in warm extremes in the future combined with the absence of adaptation may lead to a reduction of the human life span of up to 3-4 months in 2070-2100 (Ballester et al. 2011).

Since climate change is expected to increase the existing risk levels associated not only with heat waves but also with other natural hazard types, risk assessment should be the starting point for managing and reducing these risks. Moreover, risk assessment is the basis of cost-benefit analysis of risk reduction strategies and better prioritisation of public investment and development planning (ISDR 2010). For this reason, the EC (European Commission) published in 2010 a commission staff working paper on "Risk Assessment and Mapping Guidelines for Disaster Management" (EC 2010). The main purpose of the guidelines was to improve coherence and consistency among the risk assessment procedures in EU member states.

The methodology presented here considers the EC guidelines, while its major concern is to tackle the problem of data availability, which is always a major drawback in the risk assessment process. The common methodology for risk assessment and mapping is presented through an application example for heat waves in Romania.

\subsection{Risk and vulnerability to heat waves}

In order to be able to assess vulnerability and risk to heat wave, the impact of the heat wave on the people, the ecosystem and the infrastructure has to be clearly identified.

Heat waves are related to an increased human mortality, and therefore, various studies attempted to identify temperature thresholds beyond which negative health impacts are

Table 1 The most important heat wave events in Europe since 2003 (EM-DAT)

\begin{tabular}{lll}
\hline Most affected countries & Date & Number of victims \\
\hline Russia & June 2010 & 55,736 \\
Italy & July 2003 & 20,089 \\
France & August 2003 & 19,490 \\
Spain & August 2003 & 15,090 \\
Germany & August 2003 & 9355 \\
Portugal & August 2003 & 2696 \\
France & July 2006 & 1388 \\
\hline
\end{tabular}


expected (Wilhelmi and Hayden 2010). McGregor et al. (2007) provide a review of such thresholds and related mortality rates. The increase in mortality is related to the physical phenomenon itself, and it is related to the magnitude and the duration of the anomalous heat (McGregor et al. 2007). However, the negative health impacts also depend on a number of factors that affect the sensitivity of the population to the increased temperature (health condition, age, etc.) as well as, their ability to respond and to cope to the heat exposure (Wilhelmi and Hayden 2010).

For these reasons, vulnerable population groups to heat waves include the elderly, infants and children, people with chronic diseases and people taking certain medication (WHO Regional office for Europe 2008). Moreover, especially vulnerable are people with low socio-economic status (e.g. ethnicity, occupation and education) as well as people characterised by social isolation and homeless people. Additionally, people with occupations that require them to work outdoors (e.g. builders and athletes) are also very vulnerable to heat waves (Mattchies et al. 2008). The effects of heat waves on humans are not equally distributed in the different regions. A study investigating the geographical differences on the mortality in Europe caused by heat waves (Sunyer 2010) concluded that long duration of heat waves plays a bigger role in mortality than intensity; however, these geographical differences in mortality in Europe could only be explained by contextual characteristics related to the health system, the housing conditions, the elderly care, the type of urbanisation, construction material, air conditioning and plans of action (Sunyer 2010).

Not only humans but also ecosystems may be affected by high temperatures. For example, according to Fischlin et al. (2007) a temperature increase of 2-3 degrees Celsius can also increase the risk of extinction of $20-30 \%$ of the studied animal and plant species. More specifically, heat waves may affect ecosystems by reducing water availability but also by decreasing net ecosystem carbon dioxide $\left(\mathrm{CO}_{2}\right)$ exchange (IPCC 2012). The impact of heat waves on ecosystems may have also indirect economic effects for the affected community. For example, during the European heat wave of 2003 drought stress impacts on vegetation resulted in reduced gross primary production (GPP) in Europe by $30 \%$ (Fischlin et al. 2007). Last but not least, the impact of heat waves on vegetation results also in increased flammability which increases the risk of wildfires.

Heat waves have also a negative impact on infrastructure. As far as the electricity network is concerned, the high temperatures and their effect on materials have to be managed in combination with the increased demand for electricity due to the excessive use of air conditions (QUT 2010).

According to McColl et al. (2012) and Chapman et al. (2013), urban electricity networks are the most susceptible of all the critical infrastructure networks to high temperatures. This is due to the impact of high temperatures on transformers that lead to reduction in efficiency and life span. However, the interaction between critical infrastructures networks (e.g. the electrification of transport networks) should also be taken into consideration (Chapman et al. 2013). Regarding the transport infrastructure, high temperatures may cause buckling of rail tracks and also discomfort of the passengers if not adequate air conditioning is available. Transport may also be affected indirectly due to electrical faults. The surface of highways, roads and other transport networks (e.g. bicycle routes and pavements) may also be damaged by the heat (QUT 2010). In more detail, extreme temperatures may cause road surface softening, traffic-related rutting, buckling of pavements and flushing or bleeding of asphalt, which will have a direct effect of the maintenance costs (Mills and Andrey 2002). As far as the rail tracks are concerned, misalignments due to high temperature may lead to derailments (Rossetti 2002; Peterson et al. 2008) as well as 
increased reaction times and reduced alertness of drivers and train engineers (Rowland et al. 2007; Vajda et al. 2014). As far as the vulnerability of transport to extreme weather events is concerned, vulnerability indicators for each mode of transport were developed within the EU project EWENT for each EU member state (Molarius et al. 2014). However, a major concern is the effect of heat waves on the water infrastructure. Water shortage related to high temperatures may cause power cuts and insufficient drinking water supplies (Jendritzky 1999).

According to Chow et al. (2012) citing Turner et al. (2003), "Vulnerability of human populations to extreme temperatures and other environmental hazards is usually defined as the degree to which they are likely to experience harm due to exposure" (page 3). Wilhelmi and Hayden (2010) developed a framework (Fig. 1) that stresses the need to better comprehend the societal vulnerability to heat-related hazards.

The framework incorporates three interactive components: exposure, sensitivity and adaptive capacity. Each component depends on a set of indicators, and it affected by external drivers, e.g. climate or socio-economic change.

For example, QUT (2010) introduces two categories of factors that affect human vulnerability and risk to heat waves: the contextual risk factors and the compositional ones. Hereby, the contextual risk factors include:

- Socio-economic characteristics (education, income and ethnic background),

- Housing and urban environment (housing material, insulation, floor of residence, etc.)

- Climate control of internal environments (e.g. availability of air conditioning)

- Homelessness (often in combination with drug use or poor health)

- Ethnic background

- Physical activity

The compositional risk factors contain:

- Age

- Pre-existing medical condition (e.g. cardiovascular disease, diabetes and obesity)

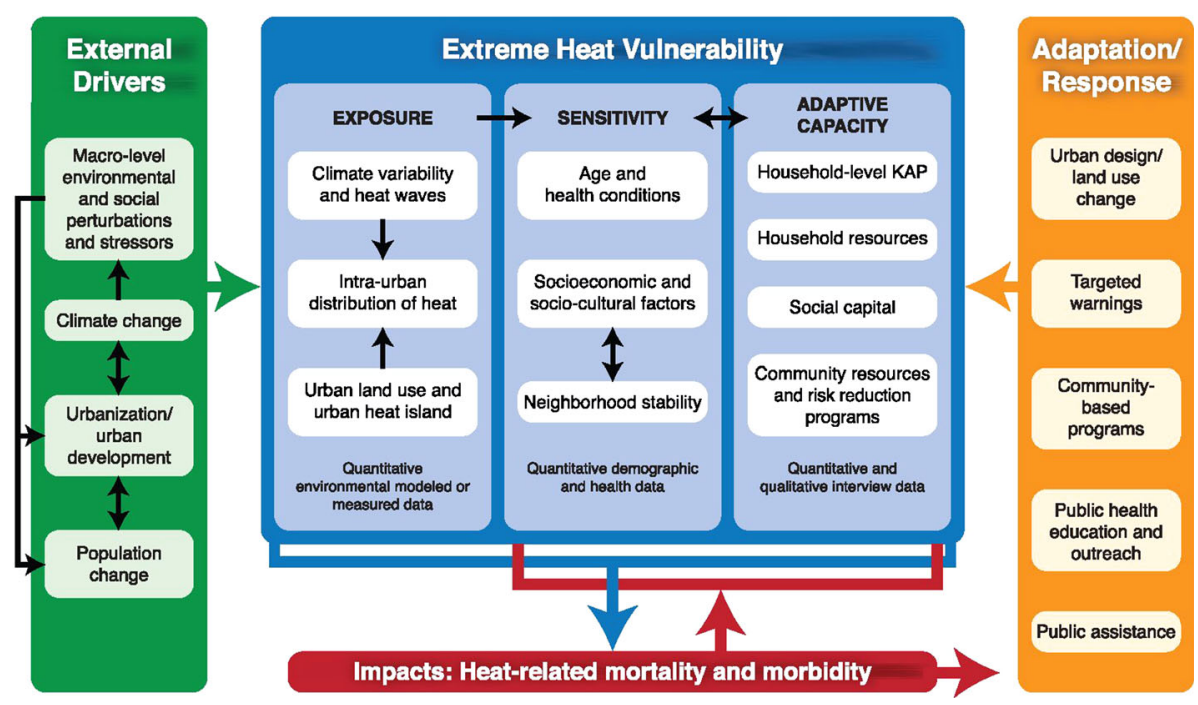

Fig. 1 Extreme heat vulnerability analysis framework (Wilhelmi and Hayden 2010) 
- Medication (drugs with thermoregulatory effects (QUT 2010)

In order to assess and map risk to heat waves in urban areas, often a heat wave vulnerability index is developed and calculated based on socio-economic characteristics of the affected population, combined with a hazard index or information regarding the spatial variation of the UHI (Urban Heat Island) (Wolf and McGregor 2013; Buscali et al. 2012; Senf and Lakes 2011; Loughnan et al. 2012). In more detail, Loughnan et al. (2012) use a number of risk factors in order to develop a vulnerability index for heat waves and visualise its spatial distribution. These factors are environmental (dwelling type, population density, intensity of urban heat island), health (burden of disease, proportion of residents with disability) and demographic (age groups, socio-economic status, persons living alone and ethnic groups) (Loughnan et al. 2012). The resulting vulnerability maps provide useful information for policy advisors, urban planners, healthcare professionals and ancillary services for the development of preparedness plans at local level. In a similar way, Reid et al. (2009) developed an accumulative heat vulnerability index at national scale for the USA considering a range of vulnerability variables related to social/environmental vulnerability, social isolation, prevalence of air condition and proportion of elderly and diabetics. On the other hand, some studies, however, focused mainly on the impact of the heat waves (e.g. D'Ippoliti et al. 2010). Harlan et al. (2006) investigated the vulnerability to heat waves through heat-related inequalities within a city leading to relationships between population characteristics and microclimates of urban neighbourhoods.

Wilhelmi and Hayden (2010) also stress the fact that vulnerability analysis should be implemented at neighbourhood or local level including quantitative and qualitative analysis of societal adaptive capacities in the context of heat health outcomes. However, this analysis requires a high amount of data that often are not available, or the access is restricted due to privacy and data protection reasons.

In general, several studies have focused on the development of social vulnerability indices in contrast to a limited amount of studies concentrating on issues related to the vulnerability of critical infrastructure or ecosystems. The detailed vulnerability analysis of human vulnerability requires a large amount of data and often data that are not available in spatial form due to privacy and data protection reasons.

In the present study, the methodology applied focuses on tackling the problem of data availability. For this reason, vulnerability is not analysed based on the characteristics of the population and their location, but it is illustrated as the impact of the heat wave on the population expressed as an index depending on the number of medical interventions at neighbourhood level. The relationship between the medical interventions and the characteristics of the population has been investigated and confirmed by several studies (e.g. Dolney and Sheridan 2006). Dolney and Sheridan (2006) plotted on a map the location of ambulance response calls within a 4-year period together with census variables such as age and educational level in order to highlight the hot spots. The main aim of the present study is to demonstrate the applicability of the common methodology for risk assessment developed within the SEERISK project. The methodology was developed based on the objectives and capacities of stakeholders in south-east Europe, and for this reason it focuses on providing solutions in order to tackle the problem of inadequate or limited data which in the case of vulnerability is particularly intense. 


\section{The need for developing a common methodology for risk assessment for south-east Europe}

In south-east Europe, extreme weather events often cause significant damage and loss of life; therefore, they constitute a major concern for authorities and local people. EU-funded research projects such as SEERISK (www.seeriskproject.eu) are granted in order to find solutions in dealing with these types of hazards. In more detail, SEERISK aims at the harmonisation of the risk assessment procedures and the enhancement of joint preparedness in order to strength awareness and efficiency of action in emergencies caused by climate change in south-east Europe. The project involves 20 partners from south-east Europe (EU and non-EU), including local and regional authorities, disaster management directorates, universities and national meteorological institutes (www.seriskproject.eu).

One of the main products of the project is a common, generic and adaptable risk assessment methodology. The SEERISK common risk assessment methodology was included in the "Guideline on Climate Change Adaptation and Risk Assessment in the Danube Macro-Region" (SEERISK Consortium 2014). The methodology has been developed in order to improve the consistency in risk assessment among south-east European countries and provide the local authorities and other end-users with a tool that will enable them to conduct risk assessment and mapping for a range of hazard types, focusing on different scales and elements at risk. Although vulnerability assessment is not a direct aim of the project, vulnerability issues had to be addressed since vulnerability analysis is a large part of the risk analysis. The dimensions of vulnerability analysed depend on the elements at risk and the risk metric chosen by the users. A questionnaire

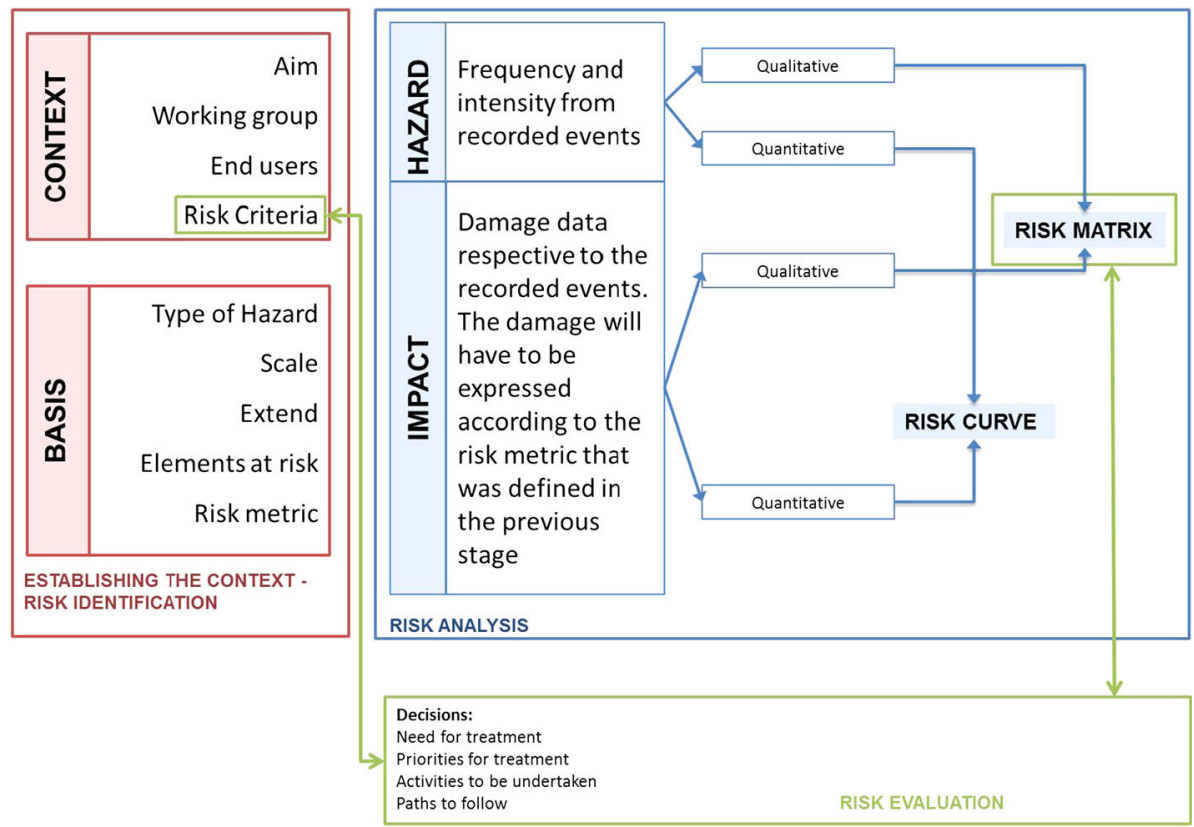

Fig. 2 Schematic flow chart of the developed SEERISK common risk assessment methodology (SEERISK Consortium 2014) 
about common practices in risk assessment and mapping, damage assessment, data availability and institutional background was completed by each partner. The results of this questionnaire were analysed and were used as a basis for the development of the common methodology. The methodology considered the EU guidelines for risk assessment and mapping (EU 2010) and the ISO31010 (IEC/FDIS 31010 2009) but also a number of existing risk assessment guidelines such as the ones from the Australian Emergency Management Committee (AEMC 2010) and from the GTZ (Deutsche Gesellschaft für Technische Zusammenarbeit, now renamed GIZ-Deutsche Gesellschaft für Internationale Zusammenarbeit 2004).

The common methodology considers drawbacks, such as lack of significant data sets, and it offers alternative steps, in order to provide a methodology that is feasible and usable even with limited data availability. As far as vulnerability is concerned, data regarding the socio-economic context such as age, income and health condition are often difficult to obtain. These data sets, if they exist, they are often not available due to data protection issues. Even if these kinds of data sets are available, they are not available in a spatial format. That means that the age distribution within a city might be known but the location of age groups is not. Moreover, since vulnerability is directly connected to the consequences of hazard, data regarding the consequences of past events are essential for the assessment of vulnerability. Poor documentation of past events, incomplete or unreliable data, as well as data in inadequate scales are the most common challenges that have to be faced. Therefore, the methodology is solution oriented, providing a stepwise approach, regarding the risk assessment procedure, offering alternatives in case one step is not possible due to lack of data.

The methodology flow chart is demonstrated in Fig. 2. The risk assessment process incorporates three steps: (1) establishing the context and risk identification, (2) risk analysis and finally and (3) risk evaluation. However, the three steps are interconnected and often overlap and run in parallel (e.g. establishment of risk criteria in step 1 and the levels of risk matrix in step 2 are used during risk evaluation, step 3).

\subsection{Context and risk identification}

During the first step of the methodology, the aim, the working group of the assessment and the end-users, as well as basis information have to be defined. The working group and the end-users will have to decide already at this stage on the risk criteria that will eventually define if a risk is acceptable and tolerable or not (e.g. number of deaths and maximum acceptable monetary loss). The basis of the risk assessment usually includes information regarding the type of hazard, the scale and the extent of the assessment, the elements at risk to be considered (buildings, people, etc.) and the risk metric (monetary loss, affected inhabitants, number of deaths, etc.) used to express risk and has to be identified at the early stage of the risk assessment process.

\subsection{Risk analysis}

The risk analysis is the largest part of the risk assessment and the one that requires the largest amount of data. It incorporates the following:

- Hazard analysis The hazard analysis includes the identification of the hazard and its triggering factors, the likelihood of occurrence and the intensity of potential event(s). A large amount of spatial and non-spatial data is required in order to analyse the hazard as 
well as data regarding past events and their characteristics. The information collected should concern the extent of the phenomenon, its frequency duration and intensity.

- Impact analysis Impact analysis focuses on the consequences of the potential hazardous phenomenon on the elements at risk. Information regarding the impact of specific events is collected and analysed on the basis of the elements a risk and risk metric decided in the previous step. Moreover, the identification of the elements at risk (exposure) in the study area and their characteristics that affect their vulnerability (vulnerability factors and indicators) have to be also included in the impact analysis.

- Risk analysis According to the EC Guidelines (2010) risk analysis in "the process to comprehend the nature of risk and to determine the level of risk". The results of the hazard and the impact analysis can be depicted on a risk matrix (Fig. 3). The intervals and the risk rating have to be decided by the working group identified in the first step and are mainly related to the aim of the risk assessment.

\subsection{Risk evaluation}

This is the last step of the risk assessment procedure. At this point, the results of the risk analysis and the risk criteria set in the first step will have to be compared on the basis of the risk criteria set at an earlier stage.

However, these steps are good for setting a theoretical basis in order to implement a risk assessment; however, in reality, the local authorities or other end-users need more specific information and solutions in case of lack of the required data. A more detailed stepwise approach to the risk assessment procedure and mapping is given in Figs. 4a-d. A number of alternatives were offered for the development of hazard and impact maps (Fig. 4-d) for qualitative (Fig. 4a, b) and quantitative (Fig. 4c, d) assessment, in order to produce a risk map following the steps presented in Fig. 5. The alternatives steps are given for qualitative and quantitative risk assessment. In the quantitative risk assessment the risk rating is expressed as a number (probability or loss), whereas in the qualitative risk assessment a qualitative description is used (very high, high, medium, low) to express the risk rating.

In more detail, in the case of hazard analysis in qualitative risk assessment (Fig. 4a), if a hazard map in the required scale is not available, the end-user may develop a heat wave hazard map by using meteorological data available for the case study area. If such data are also not available and consequently the previously mentioned analysis is also not possible,

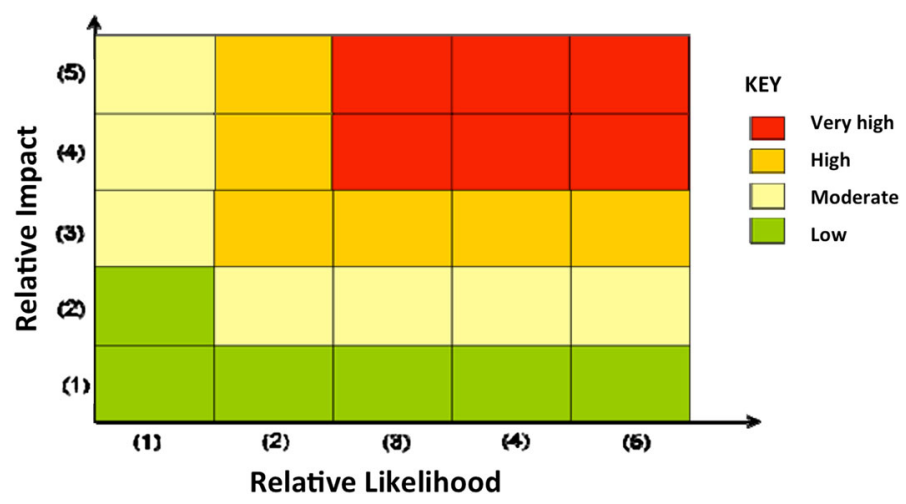

Fig. 3 Risk matrix (EC, 2010) [Note (1), (2), (3), etc. are the different ratings of impact and likelihood] 

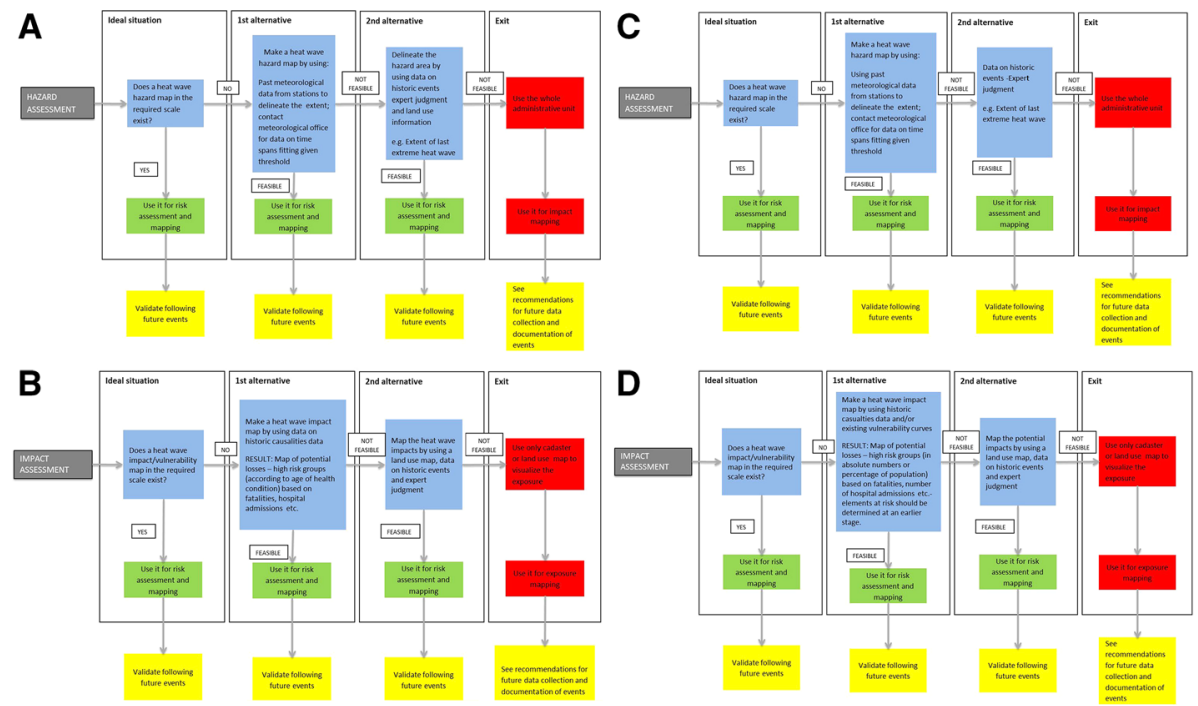

Fig. 4 a Qualitative hazard assessment for heat waves. b Qualitative impact assessment for heat waves. c Quantitative heat wave hazard assessment. d Quantitative heat wave hazard assessment (SEERISK Consortium 2014)

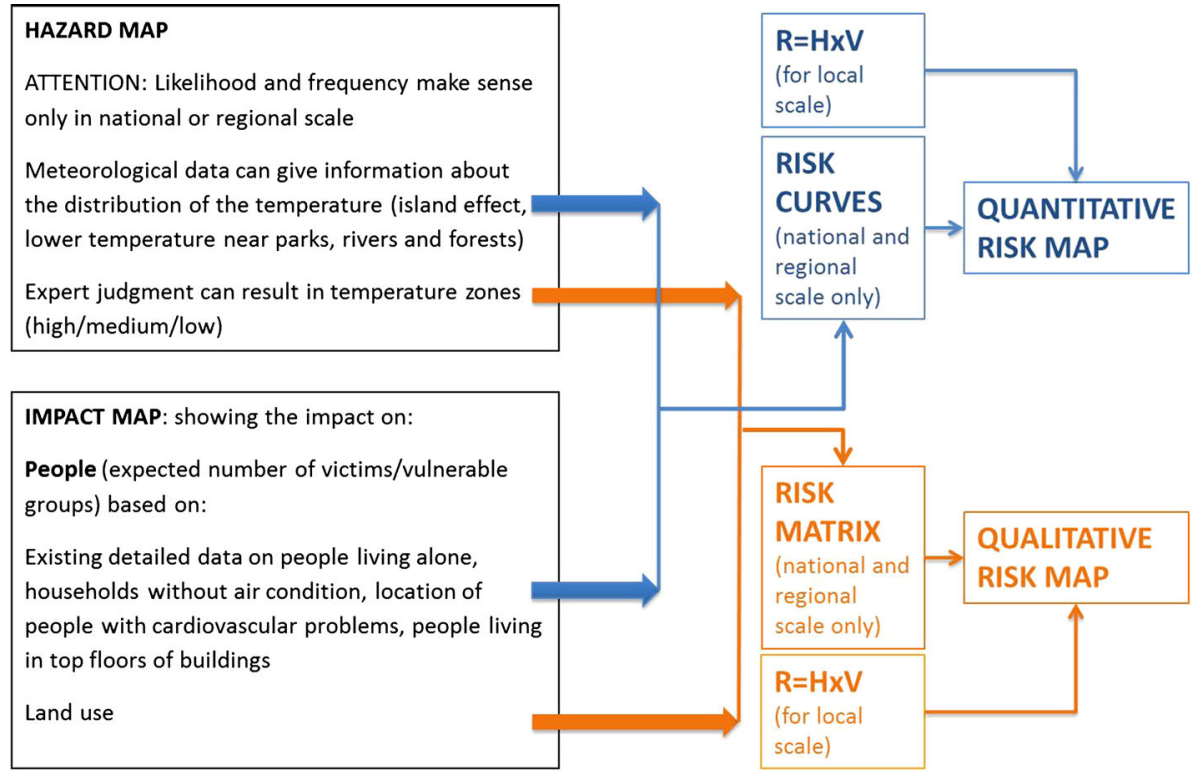

Fig. 5 Risk assessment and mapping procedure for heat waves (SEERISK Consortium 2014)

then the end-user should move to the second alternative and produce a heat wave hazard map based on expert judgement, land-use information and information from past events. In case none of this information is available, the exit option is to use the whole administrative 
unit and develop as end product an impact map. In case of quantitative risk assessment, the hazard analysis will also use similar alternative steps (Fig. 4c).

As far as the impact analysis is concerned, the end-users may follow the alternative steps shown in Fig. 4b, d in order to create an impact map or, if the availability of data is limited, an exposure map. At the end, the end products of the hazard and impact analysis will be overlaid to develop a qualitative or a quantitative risk map based on a risk matrix or a risk curve, respectively.

The common risk assessment methodology and the specific flow charts shown in Fig. 4a-d were later modified for a range of climate-related hazard types such as drought, heat wave, flood, wild fire and extreme wind. It is important to mention that for some hazards, including heat waves and droughts, the probability of occurrence at local level does not present any spatial variation. In this case, it is the intensity of the process that is taken into consideration for the hazard analysis and mapping. The aim of the specific chapter is to demonstrate the applicability of the methodology on heat wave case study and not to introduce a new heat wave risk assessment methodology as such. It is clear that the methodology is transferable to other areas susceptible to heat waves since it does not restrict the user in a specific risk metric or specific method of expressing and assessing hazard and vulnerability. Additionally, it provides alternatives in case the required data are not available, which means that it can be applied at places where complete data sets are

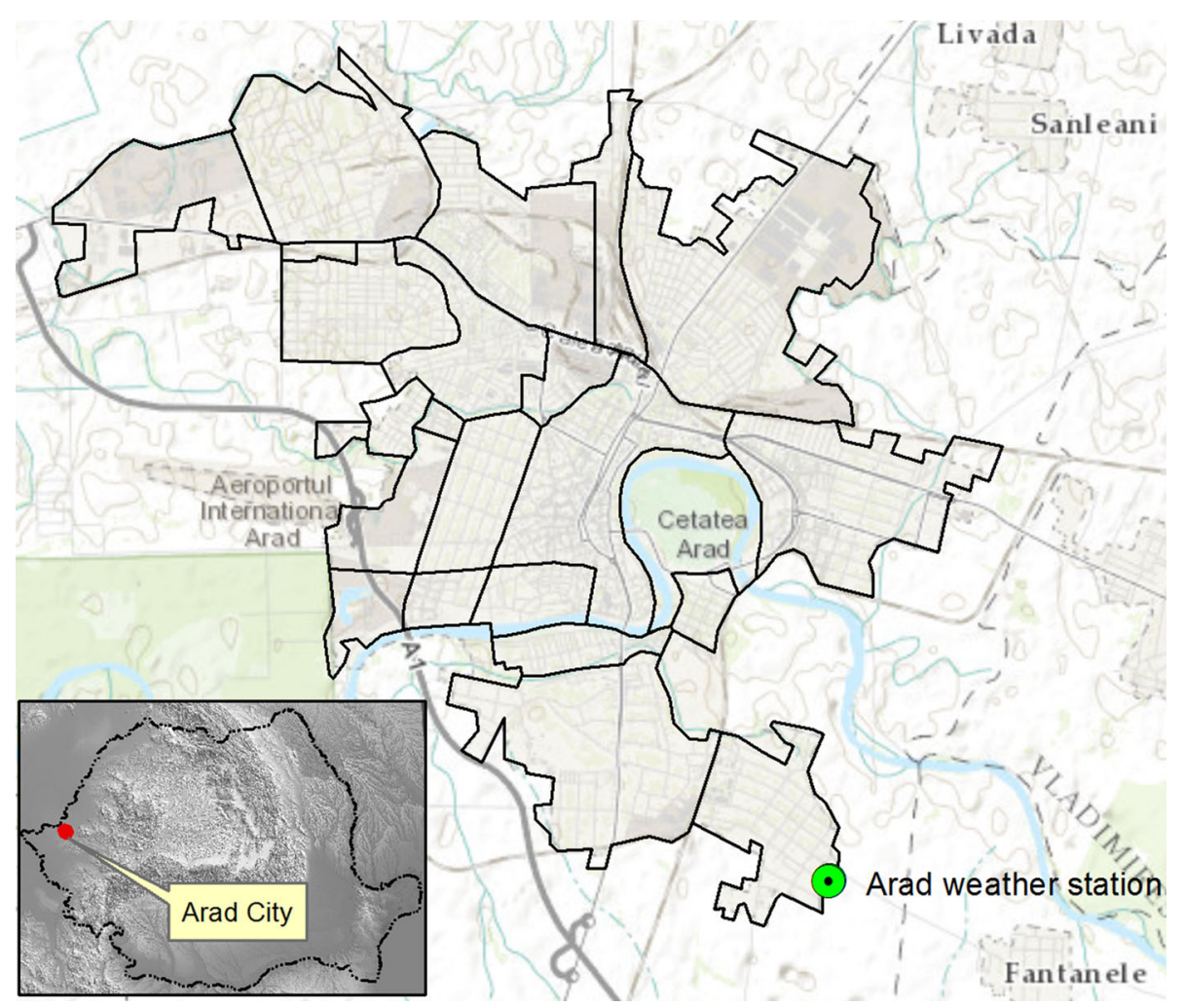

Fig. 6 Map showing the location of the study area and its surroundings (Source: National Meteorological Administration, Romania) 
available but also at places where expert judgement is the only source of information. The common methodology is, however, transferable to areas facing different climate-related hazards such as droughts, wildfires, floods and extreme winds. The methodology has already been applied in areas facing these hazards within the SEERISK project; however, the results are not presented in this chapter.

\section{The study area}

The common methodology was applied in Arad, which is the capital of Arad County in Western Romania situated very close to the border with Hungary and covers an area of $47 \mathrm{~km}^{2}$ (Fig. 5). Arad is located on the High Plain of Arad $110 \mathrm{~m}$ above sea level and is crossed by the river Mureş/Maros. It has a population of 147,922 (according to 2011 census) making it the 12th largest city in Romania and the third largest city at the western part of the country. The climate of the area is continental with Mediterranean influence characterised by cool winters and hot summers (Administraţia Naţională de Meteorologie 2008). The Lunca Mureşului (Mureş Floodplain) Natural Park, situated between Arad and the Hungarian border, is included in the Ramsar List of Wetlands of International Importance (Fig. 6). Arad is a university centre and an industrial city with important automotive, furniture and textile industries. An important power station situated in Arad connects the Romanian and Hungarian power supply systems. Moreover, the city is surrounded by large agricultural areas.

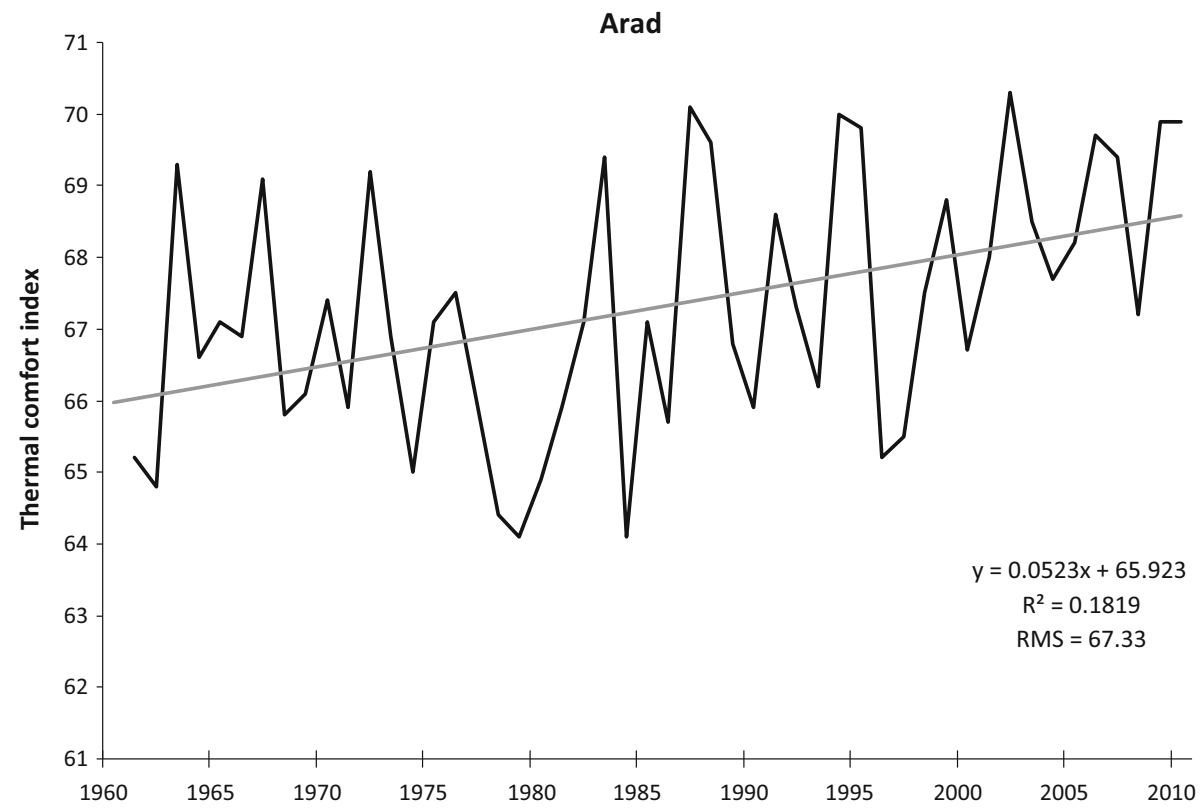

Fig. 7 Evolution of July thermal comfort index (non-dimensional units) for the municipality of Arad (Source: National Meteorological Agency, Romania). With grey line is represented the trendline (the linear regression and the associated $R$-squared and RMS value are illustrated in the bottom right corner of the figure). The data used were obtained for the meteorological station in Arad. In 1973, the location of meteorological station was changed from the airport to San Nicolau Mic district (marked in Fig. 6) 
The European Environmental Agency published the results of a study concerning historic air temperatures and projections of future scenarios (EEA 2012), which clearly shows that Arad is located within an area where according to these projections the temperature is expected to rise and heat wave events are expected to increase in the coming decades. The increase in temperature may be demonstrated through the evolution of July thermal comfort index for 1961 until 2010 for the municipality of Arad, which is shown in Fig. 7. The thermal comfort index used in Fig. 7 was developed by Masterton and Richardson (1979) at the Meteorological institute of Canada in collaboration with the health Ministry of Canada and is based on air temperature at $2 \mathrm{~m}$ from the surface and relative humidity, and it is expressing the level of discomfort experienced by the population.

Since heat waves constitute an emerging hazard for the area, the Inspectorate for Emergency Situations "Vasile Goldiş" (2012) in the county of Arad developed a "Risk Assessment and Intervention Plan" for Arad County, which includes measures for situations with prolonged temperatures and is updated every year. According to the national regulations (Monitorul Oficial 2000), heat wave is defined as "two consecutive days with air maximum temperature greater than $37{ }^{\circ} \mathrm{C}$ (or with the maximum value of thermal comfort index greater than 80)". In case of multiple medical interventions or severe medical situations within the territory of Arad county, the national regulations require that the "Red Plan" should be used in which medical interventions of all medical mobile units (public and private ambulances, SMURD teams) and public hospitals are effectively organised (Source: http://lege5.ro/ Gratuit/geztomrthe/ordinul-nr-203-2010-pentru-aprobarea-structurii-cadru-a-planuluirosu-de-interventie). According to the same source, additionally, the Public Health Directorate in Arad has its own regulations and procedures for dealing with heat waves effects (setting up tents for sheltering people walking in the streets during high-temperature periods, providing cold water, etc.) with significant support from other NGO's (Red Cross, etc.). However, no heat wave risk map has ever been developed for the area.

\section{Application of the methodology for heat wave risk assessment}

The study area is homogenous and is comprised by built-up areas (in particular, old buildings, block of flats, detached houses), gardens, small industrial areas transport networks and the main railway station of the city. The element at risk considered for the risk mapping was the local population of Arad city, and the risk metric used was the number of medical interventions per 150,000 inhabitants. Heat waves in urban areas project themselves on urban heat island, with higher temperatures being recorded in the city centre, where the intensity of urban heat island is stronger. The number of medical emergencies/
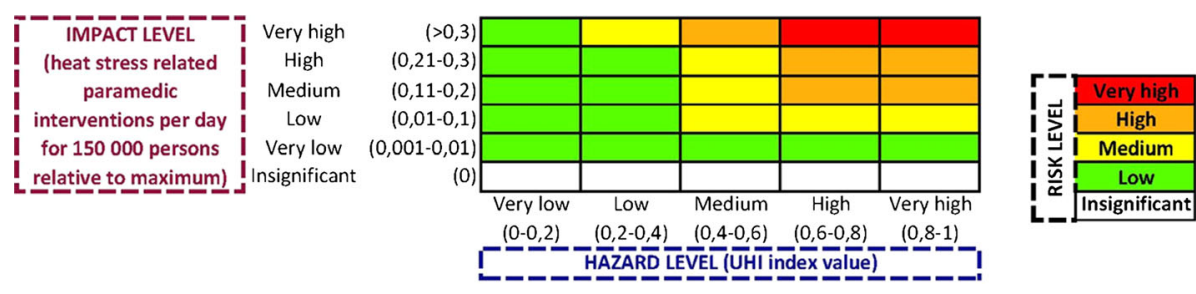

Fig. 8 Risk matrix for heat waves for the municipality of Arad 
incidents among elderly people and people with chronic diseases (cardio and lung diseases, etc.) is expected to increase due to the high temperatures. People with chronic diseases could experience discomfort because of thermal stress which amplifies the malfunctions of the body.

Based on data regarding the medical intervention during past events and the corresponding hazard level, a risk matrix was developed for the city of Arad (Fig. 8). The matrix shows in the vertical axis the impact level expressed as standardised paramedic interventions per day and in the horizontal axis the hazard level expressed as a standardised UHI (Urban heat island index) value (SEERISK Consortium 2014). Since the spatial distribution of the UHI is different during the day and during the night, two hazard maps have been developed for Arad, which show the distribution of the UHI value within the municipality during daytime and during night-time (Fig. 9).

Developing heat wave hazard maps at a local scale is challenging due to the lack of high-resolution air temperature data coming from meteorological stations. In the literature, studies can be found that tackle this problem by using satellite-derived data for land surface temperature in order to monitor urban temperature during heat waves (e.g. Dousset et al. 2011; Laaidi et al. 2012). In other studies such as the one of Keramitsoglou et al. (2013), urban climate models are developed using satellite, in situ und ancillary data regarding the surface radiation in order to map heat wave hazard. However, in the case of Arad municipality, since there is only one weather station available, satellite-derived land surface temperature is used. In our study, the day (night) UHI index is computed as the summer mean of daytime (night-time) land surface temperatures (LSTs) over an area centred on Arad municipality (at spatial resolution of $1 \mathrm{~km}$ ) divided by the highest mean value.

In more detail, building composite maps were developed with day and night values of LST only for the heat wave intervals identified from data at Arad weather station. These composite maps (not shown here) look similar to the mean maps for the whole summer period 2002-2010, which is physically consistent since the heat wave conditions just enhance the urban heat island determined by the human-built structures of the town which presumably remain unchanged in time (at least in the first-order approximation). The small differences between mean and composite maps are mainly due to the sampling variability. In this context, we consider that the LST mean for the whole interval (2002-2010)

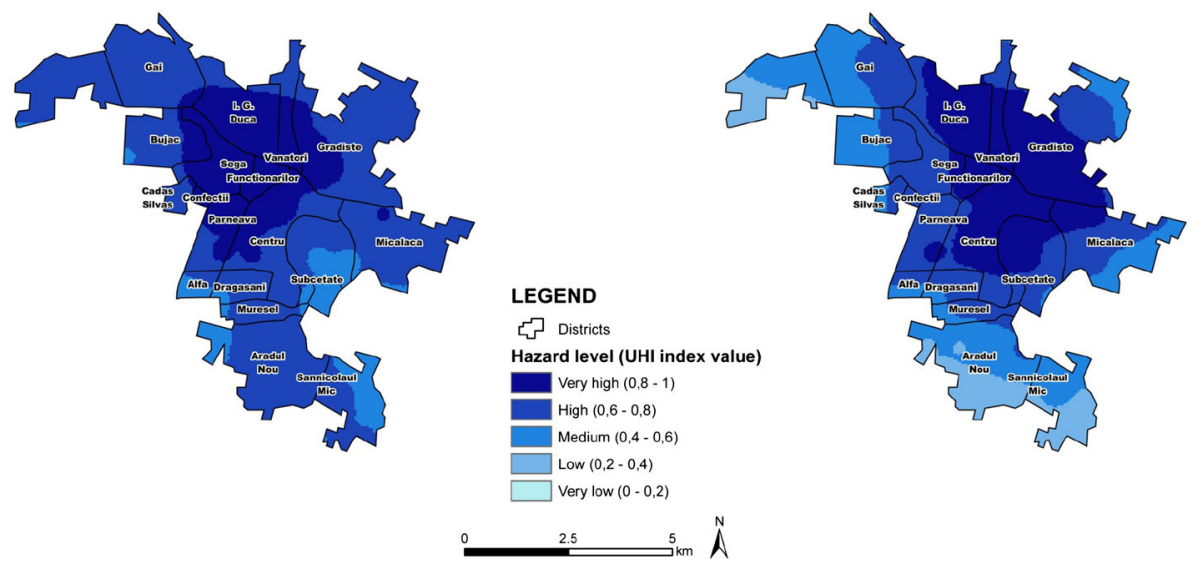

Fig. 9 Heat wave hazard in the municipality of Arad for daytime and night-time 
represents better the urban hazard structure having more samples in time to define it than the composites.

This approach was used due to: (1) the qualitative approach that was chosen for the risk assessment; (2) the definition of mean in the probability theory as the mathematical expectation. Qualitatively, the urban areas characterised by high summer LST mean have higher probability to experience the thermal stress associated with heat wave intervals.

The UHI index was normalised in order to define more easily the hazard categories and the corresponding impact categories for the risk matrix (which are also defined using a normalised impact index).

In the present study, LST from the Moderate Resolution Imaging Spectroradiometer on NASA's Aqua satellite (Aqua MODIS), as well as in situ measurements at the Arad weather station were used. Terra MODIS and Aqua MODIS view the entire Earth's surface every 1-2 days, acquiring data in 36 spectral bands or groups of wavelengths. The land surface temperature (LST) from the MODIS products is the radiometric temperature derived from the thermal infrared radiation emitted by the land surface, and measured instantaneously (Wan and Li 2011). However, the "surface" in this case is whatever satellite detects throughout the atmosphere: grass, roofs of buildings, or leaves in the canopy of a forest. Thus, LST is not the same as the air temperature $\left(T_{\text {air }}\right)$ that is measured at the weather station even though they are somehow correlated.

In the present study, daytime and night-time satellite observations of LST are used with spatial resolution of $1 \mathrm{~km}$ for the period 2002-2010. Observations at the meteorological station in Arad span a longer time interval (1973-2012). Air temperature $\left(T_{\text {air }}\right)$ is measured $2 \mathrm{~m}$ above the ground level with sensors protected from radiation and adequately ventilated to globally ensure the intercomparability between measurements at weather stations (Karl et al. 2006). It is important to emphasise that although correlated with $T_{\text {air }}$, LST differs from $T_{\text {air }}$ in its physical meaning, magnitude, and measurement techniques (Jin and Dickinson 2010).

Figure 9 shows the spatial distribution of the heat wave hazard in the city of Arad. It is clear that the hazard level is higher in the city centre and especially in the northern part where surface temperature is increased by heat trapping effect of high buildings, land surface coverage with materials characterised by high heat capacities, associated reduction in vegetation area, and the intensive use of cars and air conditions. In addition, in the
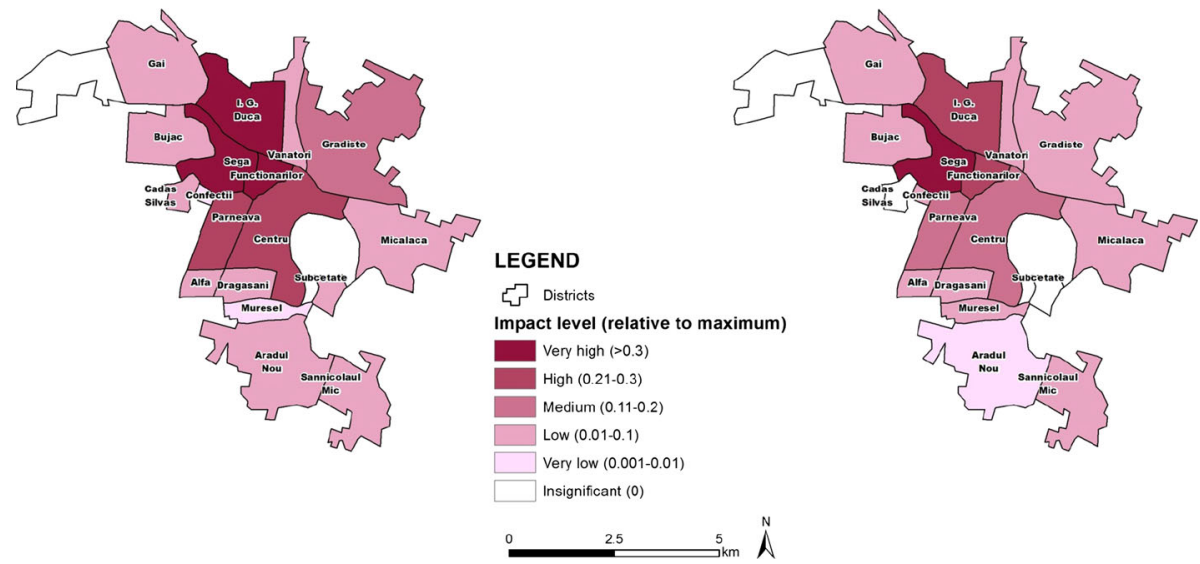

Fig. 10 Impact mapping in the municipality of Arad for daytime and night-time 
northern part of the city, the influences of green areas surrounding Arad (e.g. the natural park Lunca Muresului) seem to be at minimum level.

The next step was the creation of two impact maps (daytime and night-time) that show the level of impact expressed as a standardised index based on number of interventions related to heat stress of the emergency services per 150,000 inhabitants (Fig. 10).

The impact index is defined on district scale of Arad as the mean number of paramedic interventions per 150,000 inhabitants related to heat stress, stratified for daytime and nighttime, for the period 2009-2012 (Archive of the Emergency Situations Inspectorate "Vasile Goldiş" of County Arad-ISUJ Arad). Some studies use mortality-based impact indices (e.g. e.g. Dousset et al. 2011; Laaidi et al. 2012) to express and map heat wave impact; however, in the present study, the number of paramedic interventions related to heat stress including both morbidity and mortality data is used, since the case study constitutes a medium-sized town with medium intensity impact of heat stress. The district values of impact index are also normalised by dividing them to the highest value. We define the impact categories for the risk matrix using these normalised values of the impact index.

The high impact areas do not always coincide with the high hazard areas of the maps shown in Figs. 9 and 10, as the higher number of interventions is probably associated with characteristic of the people living there (e.g. health condition and age).

Finally, two risk maps have been created for the municipality of Arad (daytime and night-time) as it is shown in Fig. 11. In the risk matrix, the heat wave risk was rated (very high, high, medium, low) and the risk categories were assigned a corresponding colour guided by historic heat wave events and the associated impact which was found in the archive of the Emergency Situations Inspectorate "Vasile Goldiş" of County Arad-ISUJ Arad. However, this archive covers only the events recorded in the period 2009-2012. These are mainly the heat wave events that took place on 9-10 July 2011, 5-6 July 2012 and 23-25 August 2012.

There are three districts in Arad (Duca, Sega and Functionarilor) characterised by very high-risk level (red) for the daytime and one district (Sega) for the night-time. Three districts are characterised with high risk (orange coloured) during the daytime and four during the night-time. The spatial pattern of the impact during the day and during the night is rather similar (Fig. 10). However, the spatial pattern of the risk during the daytime and the night-time is slightly different. In more detail, the high-risk and very high-risk areas
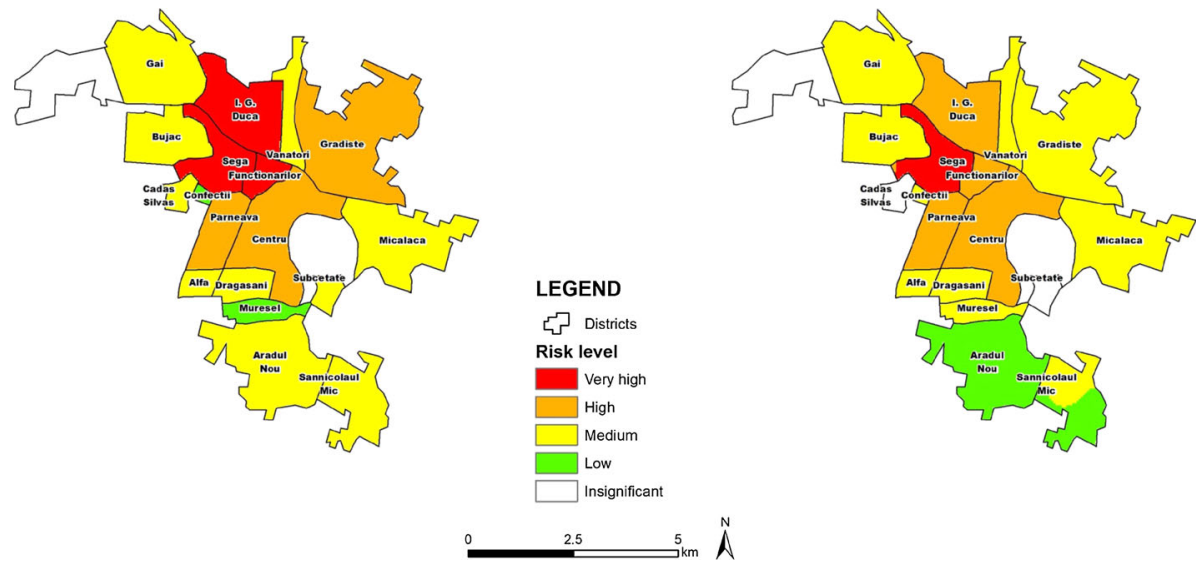

Fig. 11 Heat wave risk mapping for daytime and night-time in the municipality of Arad 
cover a larger area during the day. This can be explained by the fact that the social features of the Gradiste district, which makes the main difference between day and night risk maps, lead to less interventions during the night-time although the effects of urban heat island are very high there, too. Moreover, it is clear that the high hazard areas during the night are located at the east side of the city. This may also be related to the existence of the natural park (Lunca Mureşului) at the west side of the city. However, the specific districts are characterised of low risk at night due to low number of paramedic interventions. The low number of interventions may also be related to the socio-economic characteristics of the local population; however, at this stage, relevant information is not available.

\section{Discussion}

The application of the methodology in the city of Arad for heat waves highlighted the districts characterised by high heat wave risk and indicated the areas of the city where the local authorities, emergency planners and rescue teams should focus their efforts during a heat wave event. From the maps, it is also easy for the local authorities to see where adaptive measures have to be considered and implemented in the long term. The fact that although some districts suffer from the same level of urban heat island they do not have the same level of impact during the heat wave has to be further investigated, and the difference between the social characteristics of these areas has to be examined. Measures may be taken in the districts where the heat island effect is increased, such as increase of green space, reduction of soil sealing, provision of shaded spaces (e.g. shaded pavements for pedestrians) and redirection of traffic during hot days. On the other hand, efforts for awareness raising should be more intense in the areas where the impact is higher (e.g. Duca, Sega and Functionarilor districts) and funding for better insulation and air conditioning for the local population should be considered. The risk maps may be used by the local authorities in order to develop shelters with air condition for local people in the areas where the risk is high. Moreover, the rescue teams may use the maps in order to identify locations with higher need for intervention during the days of the heat wave and plan their actions more effectively.

The risk maps developed in the present study for the urban area of Arad are important as first approximations and a starting point for developing adaptation strategies to climate change; however, their development was restricted due to a number of limitations:

- The number of medical interventions could not be compared with the spatial distribution of socio-economic data or data regarding the land use due to lack of required data.

- Since it was impossible to develop a clear view and a spatial pattern of vulnerability indicators, no basis for developing vulnerability and risk reduction strategies may be provided at this stage. However, the risk map as it is presented here may be regarded as a preliminary result indicating some hot spots and may provide a basis for further investigation.

- Data regarding the impact were only available on district level. The availability of data on block level would give a more detailed overview of the distribution of risk within the districts but also at the border areas.

- In the present study, the development of the hazard maps is based on land surface temperatures (LSTs) taken from satellite. However, the air temperature is the variable which directly affects the population. LST is not the same as the air temperature $\left(T_{\text {air }}\right)$ 
that is measured at weather stations even though they are somehow correlated. $T_{\text {air }}$ could be derived from the satellite products and in future could be used for the development of hazard maps.

Based on the limitations of the study, a number of future perspectives and development may be identified. Improvements of both hazard and impact components of the risk assessment are envisioned. For example, an improvement of the hazard map could be the use of a thermal comfort index computed for the urban area, adding the air humidity component to the thermal one. The difference in the risk rate of districts experiencing a similar level of hazard has been explained by socio-economic differences of the inhabitants of the districts. The role of vulnerability within risk assessment is once more highlighted pointing out the need for detailed data regarding the population and its vulnerability to high temperatures. These data may include information regarding the age and health of the population, the availability of air condition as well as information on housing (e.g. insulation and number of floors). However, the present study showed that although the required data for a detailed vulnerability assessment were not available, the alternative way of expressing vulnerability by using the number of emergency interventions also leads to plausible results that may be used by the end-users for designing risk reduction measures and emergency plans. However, vulnerability of the population is only a part of the vulnerability assessment. Other dimensions of vulnerability to heat waves should also be analysed. For example, a future development of the study could include impact maps of the ecosystem (e.g. impact on agriculture) or the critical infrastructure (impact on telecommunication networks, water availability, etc.). The scale of the study is also very important. Data available at block or even at household level would give a detailed pattern of vulnerability, which would be ideal for detailed vulnerability analysis and visualisation of the spatial pattern of vulnerability to heat waves. Such detailed maps could be used for emergency planning. On the other hand, risk and vulnerability analysis at national scale could be used for funding allocation and prioritisation.

The applicability of the common risk assessment methodology was demonstrated through the heat wave case study. The methodology is reproducible since it was also applied within the SEERISK project in other case studies and for different hazard types (floods, droughts, wildfires and extreme wind). However, the results of the application on other study areas are not included in the present chapter. A future development for the study would be the applicability of the methodology to another area susceptible to heat wave hazards.

\section{Conclusions}

The present study attempts the development of risk maps for heat waves based on a risk assessment methodology, which was developed in order to give the opportunity to areas with limited or no data to develop risk maps that may be used for risk reduction, prevention and emergency management. The final products show that it is possible to develop useful products by applying the methodology; however, a number of future developments of the study that may lead to an improved overview of the vulnerability to heat waves and improved risk assessment are also listed here.

Acknowledgments Open access funding provided by University of Natural Resources and Life Sciences Vienna (BOKU). The research presented in this chapter was carried out within the framework of the project SEERISK (Project code: SEE/C/0002/2.2/X) funded by SEE (Southeast Europe Transnational Cooperation 
Programme). The authors would also like to thank the SEERISK consortium for their feedback at earlier stages of the methodology development. Last but not least, the comments of two anonymous reviewers on an earlier version contributed significantly to the improvement of the chapter.

Open Access This article is distributed under the terms of the Creative Commons Attribution 4.0 International License (http://creativecommons.org/licenses/by/4.0/), which permits unrestricted use, distribution, and reproduction in any medium, provided you give appropriate credit to the original author(s) and the source, provide a link to the Creative Commons license, and indicate if changes were made.

\section{References}

Administrația Naţională de Meteorologie (2008) Clima României, ISBN: 978-973-27-1674-8, Editura Academiei, 368 pp (in Romanian)

AEMC (Australian Emergency Management Committee) (2010) National emergency risk assessment guidelines. Australian Emergency Management Committee, Emergency Tasmanian State Emergency Service, Hobart

Ballester J, Robine JM, Herrmann FR, Rodo X (2011) Long term projections and acclimatization scenarios of temperature related mortality in Europe. Nat Commun 2:358

Buscali C, Upegui E, Viel F (2012) Mapping heatwave health risk at the community level for public health action. Int $\mathrm{J}$ Health Geogr 11-38:1-9

Chapman L, Azevedo JA, Prieto-Lopez T (2013) Urban heat and critical infrastructure networks: a viewpoint. Urban Clim 3:7-12

Chow WTL, Chuang W-C, Gober P (2012) Vulnerability to extreme heat in metropolitan phoenix: spatial, temporal and demographic dimensions. Prof Geogr 64(2):286-302

Ciscar J-C (ed) (2009) Climate change impacts in Europe: final report of the PESETA research project. JRC Scientific and Technical reports

D'Ippoliti D, Michelozzi P, Marino C, de Donato F, Menne B, Katsouzanni K, Kirchmayer U, Analitis A, Medina-Ramon M, Paldy A, Atkinson R, Kovats S, Bisanti L, Schneider A, Lefranc A, Iniguez C, Perussi CA (2010) The impact of heat waves on mortality in 9 European cities: results from the EuroHEAT project. Environ Health 9:37

Depietri Y, Renaud FG, Kallis G (2011) Heat waves and floods in urban areas: a policy oriented review of ecosystem services. Sustain Sci 7(1):95-107

Dolney TJ, Sheridan SC (2006) The relationship between extreme heat and ambulance response calls for the city of Toronto, Ontario, Canada. Environ Res 101:94-103

Dousset B, Gourmelon F, Laaidi K, Zeghnoun A, Giraudet E, Bretin P, Mauri E, Vandentorren S (2011) Satellite monitoring of summer heat waves in the Paris metropolitan area. Int J Climatol 31:313-323. doi:10.1002/joc.2222

EC (2010) Staff working paper on risk assessment and mapping guidelines for disaster management. European Commission, Brussels

EEA (European Environment Agency) (2012) Urban adaptation to climate change in Europe: challenges and opportunities for cities together with supportive national and European policies. EEA Report, No $2 / 2012$

Fischlin A, Midgley GF, Price JT, Leemans R, Gopal B, Turley C, Rounsevell MDA, Dube OP, Tarazona J, Velichko AA (2007) Ecosystems, their properties, goods, and services. In: Parry ML, Canziani OF, Palutikof JP, van der Linden PJ, Hanson CE (eds) Climate change 2007: impacts, adaptation and vulnerability. Contribution of working group II to the fourth assessment report of the intergovernmental panel on climate change. Cambridge University Press, Cambridge, UK, pp 211-272

GTZ (Deutsche Gesselschaft für Technische Zusammenarbeit) (2004) Risk analysis—a basis for disaster risk management. Guidelines, Eschborn

Harlan SL, Brazel AJ, Prashad L, Stefanov WL, Larsen L (2006) Neighbourhood microclimates and vulnerability to heat waves. Soc Sci Med 63:2847-2863

IEC (International Electrotechnical Commission)/FDIS (2009) ISO.IEC.31010:2009-Risk ManagementRisk Assessment techniques

Inspectorate for Emergency Situations "Vasile Goldi" County of Arad (2012) "Risk assessment and intervention plan" for Arad County. Available on line (in Romanian). http://www.isuarad.ro/upload/ 2012/Gestionarea\%20_riscurilor/PAAR_ARAD.pdf

IPCC (Intergovernmental Panel for Climate Change) (2012) Managing the risks of extreme events and disasters to advance climate change adaptation. In: Field CB, Barros V, Stocker TF, Qin D, Dokken 
DJ, Ebi KL, Mastrandrea MD, Mach KJ, Plattner G-K, Allen SK, Tignor M, Midgley PM (eds) A special report of working groups I and II of the intergovernmental panel on climate change. Cambridge University Press, Cambridge, UK, and New York, NY, USA, 582 pp

ISDR (International Strategy for Disaster Reduction) (2010) Strengthening climate change adaptation through effective disaster risk reduction. Briefing Note 03

Jendritzky G (1999) Impacts of extreme and persistent temperatures: cold waves and heat waves. In: UNESCO, World Meteorological Organization (WMO) Proceedings: Sub-Forum on Science and Technology in support of Natural Disaster Reduction, Geneva 6-8 July 1999, pp 43-53

Jin M, Dickinson RE (2010) Land surface skin temperature climatology: benefitting from the strengths of satellite observations. Environ Res Lett 5:044004. doi:10.1088/1748-9326/5/4/044004

Karl TR, Miller CD, Murray WL, (2006) Temperature trends in the lower atmosphere: steps for understanding and reconciling differences. In: Karl TR et al (eds) U.S. climate change science program and the subcommunication on global change research, Washington, DC

Keramitsoglou I, Kiranoudis CT, Maiheu B, De Ridder K, Daglis IA, Manunta P, Paganini M (2013) Heat wave hazard classification and risk assessment using artificial intelligence fuzzy logic. Environ Monit Assess 185(10):8239-8258

Koppe C, Kovats S, Jendritzky G, Menne B (2004) Heat waves: risks and responses. Health and Global Environmental Change. SERIES, No 2. World Health Organisation

Laaidi K, Zeghnoun A, Dousset B, Bretin P, Vandentorren S, Giraudet E, Beaudeau P (2012) The impact of heat islands on mortality in Paris during the August 2003 heat wave. Environ Health Perspect 120:2. doi:10.1289/ehp.1103532

Loughnan M, Nicholls N, Tapper NJ (2012) Mapping heat health risks in urban areas. Int J Popul Res, Article ID 518687

Masterton JM, Richardson FA (1979) Humidex: a method of quantifying human discomfort due to excessive heat and humidity. Atmospheric Environment Service, Environment Canada, p 45

Mattchies F, Bickler G, Cardenosa-Marin N, Hales S (2008) Heat-health action plans. World Health Organisation, European Regional Office

McColl L, Pali EJ, Thornton HE, Sexton DMH, Betts R, Mylne K (2012) Assessing the potential impact of climate change on the UK's electricity network. Clim Change 11:821-835

McGregor G, Pelling M, Wolf T, Gosling S (2007) Social impact of heatwaves. Science Report. SC 20061/SR6, Environment Agency, UK

Mills B, Andrey J (2002) Climate change and transportation: potential interactions and impacts. In: Proceedings of the U.S. Department of Transportation research workshop: potential impacts of climate change on transportation, Washington DC, 1-2 Oct 2002, pp 77-88

Molarius R, Könönen V, Leviäkangas P, Zulkarnain Rönty J, Hietajärvi A-M, Oiva K (2014) The extreme weather risk indicators (EXRI) for the European transport system. Nat Hazards 72:189-2010

Monitorul Oficial, Partea I nr.315 din 07/07/2000. ANEXA NORME METODOLOGICE de aplicare a prevederilov Ordonantei de urgenta a Guvernului nr 99/2000 privind masurile se pot fi aplicate in periodele cu temperaturi extreme pentru protectia persoanelor icadrate in munca, Bucuresti

Peterson TC, McGuirk M, Houston TG, Horvitz AH, Wehner MF (2008) Climate variability and change with implications for transportation. National Research Council, Washington

QUT (Queensland University of Technology) (2010) Impacts and adaptation response of infrastructure and communities to heat waves: the southern Australian experience of 2009, report for the National Climate Change Adaptation Research Facility, Gold Coast, Australia

Reid CE, O’Neil MS, Gronlund CJ, Brines SJ, Brown DG, Diez-Roux AV, Schwartz J (2009) Mapping community determinants of heat vulnerability. Environ Health Perspect 117(11):1730-1736

Rossetti M (2002) Potential impacts of climate change on railroads. In: Proceedings of the U.S. Department of Transportation research workshop: potential impacts of climate change on transportation, Washington, DC, 1-2 Oct 2002, pp 209-224

Rowland BD, Davey JD, Freeman JE, Wishart DE (2007) Road transport sensitivities to weather and climate change in Australia. In: Proceedings 30th Australasian Transport Research forum, Melbourne Australia

SEERISK Consortium (2014) Guideline on climate change adaptation and risk assessment in the Danube Macro-region, p 106

Senf C, Lakes T (2011) Assessing the vulnerability and risk to heat wave events in Germany and building a basis for further modelling. Wiechmann Verlag, Geospatial Crossroads at GI-Forum, Salzburg

Smoyer-Tomic KE, Kuhn R, Hudson A (2003) Heat wave hazards: an overview of heat wave impacts in Canada. Nat Hazards 28:463-485

Sunyer J (2010) Geographical differences on the mortality impact of heat waves in Europe. Environ Health 9:38 
Turner BL, Matson PA, McCarthy JJ, Corell RW, Christensen L, Wckley N, Hovelsrud-Broda GK, Kasperson JX, Kasperson RE, Luers A (2003) A framework for vulnerability analysis in sustainability science. Proc Natl Acad Sci 100(14):8074-8079

Vajda A, Tuomenvirta H, Juga I, Nurmi P, Jokinen P, Rauhala J (2014) Severe weather affecting European transport systems: the identification, classification and frequencies of events. Nat Hazards 72:169-188

Wan Z, Li ZL (2011) MODIS land surface temperature and emissivity. In: Ramachandran B et al (eds) Land remote sensing and global environmental change, remote sensing and digital image processing, vol 11. Springer, New York, pp 563-577

WHO Regional office for Europe (2008) Protecting health in Europe from climate change. WHO Regional Office for Europe, Copenhagen

Wilhelmi OV, Hayden MH (2010) Connecting people and place: a new framework for reducing urban vulnerability to extreme heat. Environ Res Lett 5:1-7

Wolf T, McGregor G (2013) The development of a heat wave vulnerability index for London, United Kingdom. Weather Clim Extremes 1:59-68 